\title{
SISTEM PAKAR DIAGNOSA PENYAKIT KACANG KEDELAI MENGGUNAKAN METODE CERTAINTY FACTOR
}

\author{
Novi Sri Wanti Ginting ${ }^{1}$, Anita Sindar RMS ${ }^{2}$ \\ ${ }^{1}$ STMIK Pelita Nusantara Medan Indonesia \\ E-mail: sriwantinovi@gmail.com, haito_ita@yahoo.com
}

\begin{abstract}
Abstrak
Tanaman kedelai tumbuh tidak sehat biasanya diakibatkan munculnya penyakit yang menyerang tanaman, berakibat kegagalan panen. Umumnya petani mengetahui gejala tanaman yang bermasalah hanya belum memiliki pengetahuan untuk mendiagnosa penyakit tanaman dan membutuhkan modal yang cukup besar untuk memusnahkan penyerang tanaman. Penerapan sistem informasi kepakaran merupakan salah satu implementasi sistem yang terkomputerisasi dalam bidang pertanian. sistem pakar juga dapat memberikan alasan atas saran atau kesimpulan yang ditemukannya. Sistem pakar digunakan untuk memecahkan masalah yang memang sulit untuk dipecahkan dengan pemprograman biasa. Dengan Certainty Factor, mengasumsikan nilai keyakinan seorang pakar. Berdasarkan studi kasus hasil perhitungan Certainty Factor dengan nilai tertinggi yaitu 0,870418 yang artinya penyakit kacang kedelai mengalami penyakit penggulung daun dengan nilai keyakinan $87,0 \%$.
\end{abstract}

Kata kunci: sistem pakar, nilai keyakinan, certainty factor

\section{Pendahuluan}

Kacang kedelai termasuk tanaman polong-polongan. Kedelai dibudidayakan dilahan sawah maupun lahan kering. Penanaman biasanya dilakukan pada akhir musim penghujan setelah panen padi. Walau sudah sering menanam kacang kedelai, petani belum dapat menentukan secara pasti penyakit tanaman dan cara memperkecil serangan penyakit. Dalam penelitian berjudul, patogenitas beberapa cendawan entomopatogen (lecanicillium lecanii, metarhizium anisopliae, danbeauveria bassiana) terhadap aphis glycines pada tanaman kedelai pertanaman kedelai di Indonesia menghadapi permasalahan utama [1]. Kehadiran seorang pakar berperan memberikan informasi sebuah bidang yang telah digeluti sehingga mampu mengkaji secara ilmu pengetahuan sebab akibat sebuah permasalahan. Dengan sumber informasi dari kepakaran, metode Certainty Factor (CF) dapat digunakan mengatasi permasalahan penyakit yang mengganggu tanaman kacang kedelai [2]. Pengembangan aplikasi sistem pakar untuk diagnosa penyakit pada kacang kedelai menggunakan metode certainty factor ini yaitu suatu metode untuk membuktikan apakah suatu fakta itu pasti ataukah tidak pasti dan juga menggambarkan tingkat keyakinan pakar terhadap permasalahan yang sedang dihadapi.

\section{Tinjauan Literatur}

Beberapa aktivitas pemecahan permasalahan sistem pakar yaitu pembuatan keputusan (decicion making), pemaduan pengetahuan (knowledge fusing), pembuatan desain (designing), perencanaan (planning), prakiraan (forecasting), pengaturan (regulating), pengendalian (controling), diagnosis (diagnosing), perumusan (prescribing), penjelasan (explaning), pemberian nasihat (advising) dan pelatihan (tutoring) [3].

$\begin{array}{ll}\text { Dikirim } & : 2018-08-11 \\ \text { Diterima } & : 2018-12-10 \\ \text { Diterbitkan } & : 2018-12-20\end{array}$




\subsection{Sistem Pakar}

Sistem pakar adalah sistem berbasis komputer yang menggunakan pengetahuan, fakta, dan teknik penalaran dalam memecahkan masalah yang baisanya hanya dapat dipecahkan oleh seorang pakar dalam bidang tersebut (Martin dan Oxman, 1988) [4]. Sistem pakar adalah suatu sistem yang dirancang untuk dapat menirukan keahlian seorang pakar dalam menjawab pertanyaan dan memecahkan suatu masalah sehingga dapat menyelesaikan masalah serta mengambil keputusan yang biasanya dilakukan layaknya seorang pakar [5].

\subsection{Certainty Factor}

Teori Certainty Factor adalah Faktor kepastian (certainty factor) menyatakan kepercayaan dalam sebuah kejadian (fakta atau hipotesa) berdasar bukti atau penilaian pakar. Certainty factor menggunakan suatu nilai untuk mengasumsikan derajat keyakinan seorang pakar terhadap suatu data. Secara umum Teori Certainty Factor ditulis dalam suatu interval : Certainty factor menggunakan suatu nilai untuk mengasumsikan derajat keyakinan seorang pakar terhadap suatu data [6], [7].

Keterangan :

$$
\mathrm{CF}[\mathrm{H}, \mathrm{E}]=\mathrm{MB}[\mathrm{H}, \mathrm{E}]-\mathrm{MD}[\mathrm{H}, \mathrm{E}]
$$

$\mathrm{CF}(\mathrm{H}, \mathrm{E})=$ certainty factor hipotesa yang dipengaruhi oleh evidence e diketahui dengan pasti.

$\mathrm{MB}(\mathrm{H}, \mathrm{E})=$ measure of belief terhadap hipotesa $\mathrm{H}$, jika diberikan evidence $\mathrm{E}$ (antara 0 dan 1).

$\mathrm{MD}(\mathrm{H}, \mathrm{E})=$ measure of disbelief terhadap evidebce $\mathrm{H}$, jika diberikan evidance $\mathrm{E}$ (antara 0 dan 1) Certainty factor untuk kaidah premistunggal.

$$
\mathrm{CF}[\mathrm{H}, \mathrm{E}] 1=\mathrm{CF}[\mathrm{H}] * \mathrm{CF}[\mathrm{E}]
$$

Certainty Factor untuk kaidah dengan kesimpulanyang serupa (similarly concluded rules):

$\mathrm{CF}$ combineCF[H,E] $1,2=\mathrm{CF}[\mathrm{H}, \mathrm{E}] 1+\mathrm{CF}[\mathrm{H}, \mathrm{E}] 2 *[1-\mathrm{CF}[\mathrm{H}, \mathrm{E}] 1]$

$\mathrm{CF}$ combineCF[H,E]old,3=CF[H,E]old $+\mathrm{CF}[\mathrm{H}, \mathrm{E}] 3 *(1-\mathrm{CF}[\mathrm{H}, \mathrm{E}]$ old $]$

\section{Metodologi}

\subsection{Sumber Data}

a. Jenis-jenis penyakit pada tanaman kacang kedelai :

Penggulung Daun (P01), Karat Daun (P02), Ulat Gerayak (P03), Penggerek Polong (P04), Penggerek Batang Belalang (P05).

b. Jenis-jenis gejala penyakit pada tanaman kacang kedelai :

Daun Tergulung (G01), Berwarna Coklat Hitam (G02), Terdapat Bintik-Bintik Kecil Berubah (G03), Ulat Membentuk Gulungan (G04), Ulat Memakan Daun (G05), Bintik-Bintik Kecil (G06), Bercak Kecil (G07), Bercak Karat (G08), Daun Menjadi Kering (G9), Daun Berwarna Agak Putih (G10), Bagian Daging Akan Terlihat (G11), Daun Terserang Akan Berlubang (G12), Tanaman Menjadi Gundul Tanpa Daun (G13), Memakan Biji Kedelai Yang Masih Utuh (G14), Ulat Menyebabkan Kerusakan Pada Polong Muda Dan Tua (G15), Ulat Sering Merusak Bunga (G16), Biji Tidak Berkembang Dan Polong Rontok (G17), Tingkat Serangan Tinggi (G18), Bintik- Bintik Putih Pada Daun (G19), Ranting Digerek Menjadi Patah (G20), Lubang Gerakan 
Larva Pada Daun (G21), Terdapat Robekan (G22), Daun Merusak Tulang (G23), Daun Menguning (G24), Batang Daun Menjadi Menciut (G25).

\subsection{Perancangan Sistem}

Pemodelan aplikasi sistem pakar untuk mendiagnosa penyakit pada kacang kedelai berdasarkan gejala-gejala yang dialami tanaman kacang kedelai menggunakan pemodelan UML (Unified Modeling Language).

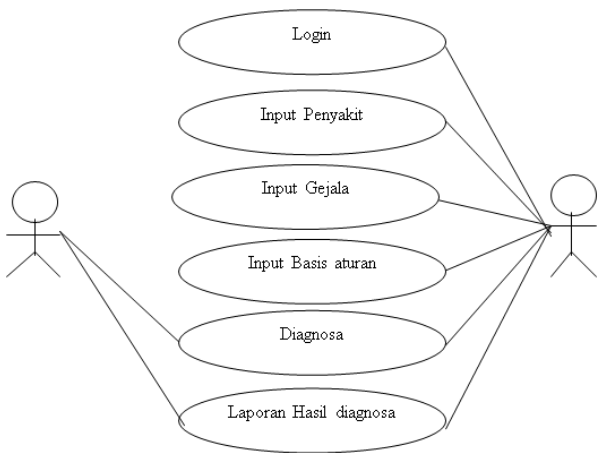

Gambar 1 : Use Case Diagram

\section{Hasil dan Diskusi}

Logika metode certainty factor pada sesi konsultasi sistem, pengguna konsultasi diberi pilihan jawaban yang masing-masing memiliki bobot sebagai berikut :

Tabel 1 : Logika Metode certainty factor

\begin{tabular}{|c|l|c|}
\hline No & \multicolumn{1}{|c|}{ Keterangan } & Nilai User \\
\hline 1 & Tidak & 0.2 \\
\hline 2 & Tidak tahu & 0.4 \\
\hline 3 & Sedikit yakin & 0.6 \\
\hline 4 & Cukup yakin & 0.8 \\
\hline 5 & Yakin & 1 \\
\hline 6 & Sangat yakin \\
\hline
\end{tabular}

Nilai 0 menunjukkan bahwa pengguna konsultasi menginformasikan bahwa user tidak mengalami gejala seperti yang ditanyakan oleh sistem. Semakin pengguna konsultasi yakin bahwa gejala tersebut memang dialami manusia, maka semakin tinggi pula hasil prosentase keyakinan yang diperoleh. Proses penghitungan presentase keyakinan diawali dengan pemecahan sebuah kaidah yang memiliki premis majemuk, menjadi kaidah-kaidah yang memiliki premis tunggal.Kemudian masing-masing aturan baru dihitung certainty factornya, sehingga diperoleh nilai certainty factor untuk masing-masing aturan, kemudian nilai certainty factor tersebut dikombinasikan.

Penetapan Nilai Kepastian (MB) dan Nilai KetidakPastian (MD), Tabel 2.

Tabel 2 : Jenis Penyakit Kacang Kedelai beserta Nilai MB dan MD

\begin{tabular}{|c|c|c|c|c|c|}
\hline No. & Kode Penyakit & Nama Penyakit & Kode Gejala & MB & MD \\
\hline \multirow[t]{4}{*}{1} & $\mathrm{P} 01$ & Penggulung Daun & G01 & 0.78 & 0.15 \\
\hline & & & G02 & 0.6 & 0.05 \\
\hline & & & G03 & 0.87 & 0.1 \\
\hline & & & G05 & 0.6 & 0.1 \\
\hline \multirow[t]{2}{*}{2} & $\mathrm{P} 02$ & Karat Daun & G06 & 0.6 & 0.15 \\
\hline & & & G07 & 0.8 & 0 \\
\hline
\end{tabular}




\begin{tabular}{|l|l|l|l|l|l|}
\hline & & & G08 & 0.5 & 0.1 \\
\hline & & & G09 & 0,8 & 0.05 \\
\hline 3 & P03 & Ulat Gerayak & G10 & 0.8 & 0.2 \\
\hline & & & G11 & 0.77 & 0.1 \\
\hline & & & G12 & 0.87 & 0.2 \\
\hline & & & G13 & 0.6 & 0.2 \\
\hline 4 & P04 & Penggerek Polong & G14 & 0,6 & 0,5 \\
\hline & & & G15 & 0,5 & 0,1 \\
\hline & & & G16 & 0,75 & 0,1 \\
\hline & & & G17 & 0,57 & 0,1 \\
\hline 5 & P05 & Penggerek Batang & G18 & 0,75 & 0,1 \\
\hline & & & G19 & 0,6 & 0,2 \\
\hline & & & G20 & 0,55 & 0,1 \\
\hline & & & G21 & 0,6 & 0,15 \\
\hline 6 & P06 & Belalang & G22 & 0,75 & 0,5 \\
\hline & & & G23 & 0,75 & 0,1 \\
\hline & & & G24 & 0,5 & 0,1 \\
\hline & & & G25 & 0,7 & 0,2 \\
\hline
\end{tabular}

Contoh kasus perhitungan Certainty Factor secara manual analisis kebutuhan input adalah termasuk kedalam jenis penyakit apa yang dialami pada kacang kedelai. Berikut adalah gejala-gejala yang terlihat pada tanaman kacang kedelai, Tabel 3.

Tabel 3 : Gejala-gejala Penyakit Tanaman Kacang Kedelai

\begin{tabular}{|l|l|c|c|}
\hline Kode & Gejala & MB & MD \\
\hline G01 & Ada daun tergulung & 0,78 & 0,15 \\
\hline G02 & Berwarna coklat hitam & 0,6 & 0,05 \\
\hline G03 & Terdapat bintik - bintik kecil berubah & 0,87 & 0,1 \\
\hline G06 & Bintik - bintik kecil & 0,6 & 0,15 \\
\hline 607 & Bercak kecil & 0,8 & 0 \\
\hline
\end{tabular}

Perhitungan Certainty Factor :

1. Nilai CF untuk G01

$$
\mathrm{CF}=\mathrm{MB}[\mathrm{h}, \mathrm{e}]-\mathrm{MD}[\mathrm{h}, \mathrm{e}] \quad=0,78-0,15=0,63
$$

2. Nilai $\mathrm{CF}$ untuk $\mathrm{G} 02$

$$
\mathrm{CF}=\mathrm{MB}[\mathrm{h}, \mathrm{e}]-\mathrm{MD}[\mathrm{h}, \mathrm{e}] \quad=0,6-0,05=0,55
$$

3. Nilai $\mathrm{CF}$ untuk G03

$$
\mathrm{CF}=\mathrm{MB}[\mathrm{h}, \mathrm{e}]-\mathrm{MD}[\mathrm{h}, \mathrm{e}] \quad=0,87-0,1=0,77
$$

4. Nilai $\mathrm{CF}$ untuk G06

$$
\mathrm{CF}=\mathrm{MB}[\mathrm{h}, \mathrm{e}]-\mathrm{MD}[\mathrm{h}, \mathrm{e}] \quad=0,6-0,15=0,6-0,15=0,45
$$

5. Nilai $\mathrm{CF}$ untuk G07

$$
\mathrm{CF}=\mathrm{MB}[\mathrm{h}, \mathrm{e}]-\mathrm{MD}[\mathrm{h}, \mathrm{e}] \quad=0,8-0=0,8
$$

Dari data di atas terdapat beberapa gejala yang berdasarkan penyakit yang akan dikombinasikan nilai $\mathrm{CF}$ dari masing - masing gejala yaitu dengan menggunakan rumus sebagai berikut :

Cf combine $(\mathrm{CF} 1, \mathrm{CF} 2)=\mathrm{CF} 1+\mathrm{CF} 2 *(1-\mathrm{CF} 1)$

a. Nilai CF kombinasi Penyakit Penggulung Daun $=\mathrm{P} 01$

CF combine $(\mathrm{G} 01, \mathrm{G} 02)=0,63+055 *(1-0,63)=0,4366 \mathrm{cf}$ old

Kombinasikan Cf old dan CF G03

Cf combine CF old dan CF G03 = 0,4366 + 0,77 * $(1-0,4366)=0,870418$ Cf old

b. Nilai CF kombinasi Penyakit Karat Daun $=\mathrm{P} 02$

Cf combine $(\mathrm{G} 06, \mathrm{G} 07)=0,45+0,8 *(1-0,45)=0,6875 \mathrm{Cf}$ old

Untuk penyakit Ulat Gerayak, Penggerek Polong, Penggerek Batang dan Belalang tidak dihitung CF combinasinya karena dari gejala yang dipilih tidak ada penyakit terkait. Dengan demikian dari proses perhitungan di atas dapat dikatakan bahwa menurut perhitungan certainty factor, diambillah nilai tertinggi yaitu 0,870418 yang artinya penyakit kacang kedelai mengalami penyakit penggulung daun dengan nilai keyakinan $\mathbf{8 7 , 0} \%$. 
Tampilan form hasil perancangan sistem :

Form Data Penyakit, Gambar 2 digunakan untuk menginput data-data penyakit. Form Data Gejala adalah form yang digunakan untuk mengelola data Gejala penyakit pada tanaman kedelai yang ada pada Sistem, Gambar 3. Form Basis Rule adalah form yang digunakan untuk mengelola data hubungan antara Gejala dan Penyakit (rule) pada tanaman kedelai yang ada pada sistem, Gambar 4. Form Diagnosa adalah form yang akan digunakan oleh user untuk Menghitung gejala yang dipilih dengan menggunakan algoritma Certainty Factor yang nantinya akan menghasilkan hasil diagnosa penyakit dan penanganannya, Gambar 5.

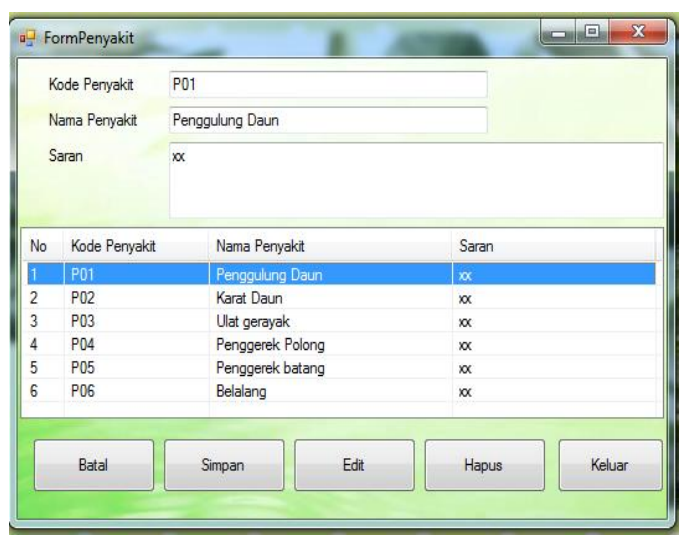

Gambar 2 : Form Data Penyakit

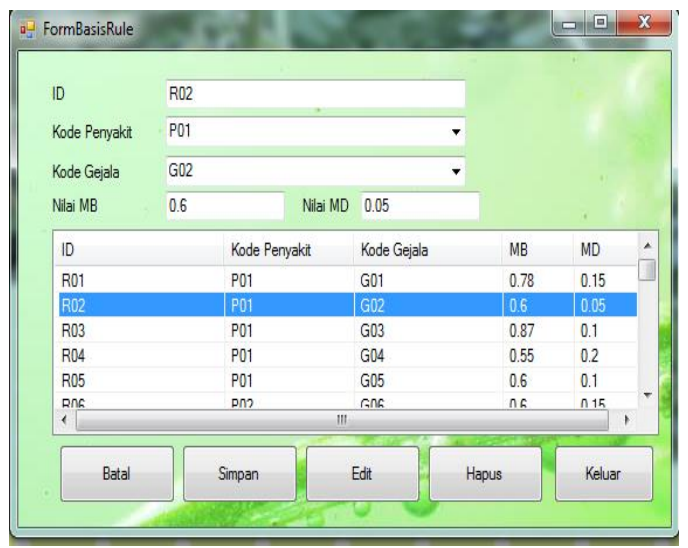

Gambar 4 : Form Basis Rule

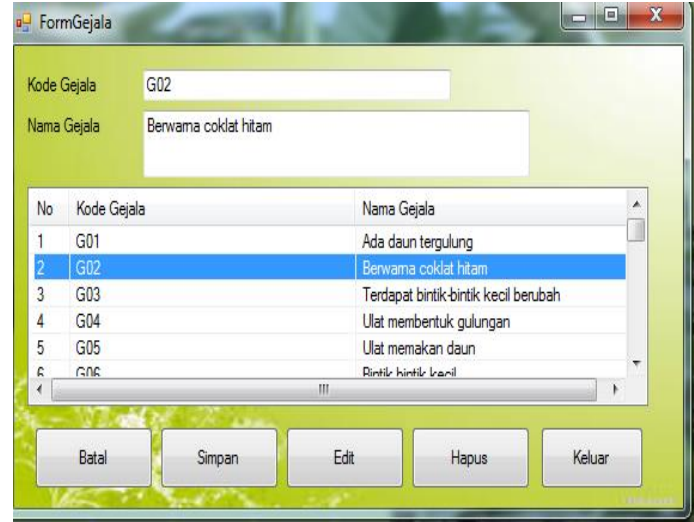

Gambar 3 : Form Data Gejala Penyakit

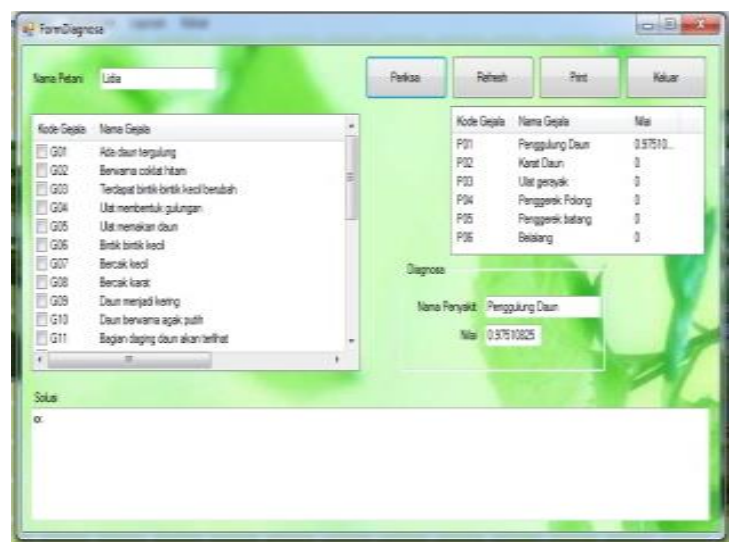

Gambar 5 : Form Diagnosa

\section{Kesimpulan}

Berdasarkan pengembangan yang telah dilakukan selama proses perancangan hingga implementasi sistem pakar mendiagnosa penyakit pada tanaman kacang kedelai dengan menggunakan Metode Certainty Factor maka dapat diambil kesimpulan sebagai berikut :

1. Sistem pakar dengan metode Certainty Factor dapat dipergunakan untuk mendiagnosa penyakit pada tanaman kacang kedelai dengan masukan berupa gejala yang dapat menghasilkan nilai perhitungan beserta penyakitnya.

2. Proses perhitungan menurut certainty factor, diperoleh nilai tertinggi yaitu 0,870418 yang artinya penyakit kacang kedelai mengalami penyakit penggulung daun dengan nilai keyakinan $87,0 \%$. 


\section{Referensi}

[1] Riri Widariyanto, Mukhtar Iskandar Pinem, Fatimah Zahara, "Patogenitas Beberapa Cendawan Entomopatogen (Lecanicillium lecanii, Metarhizium anisopliae, dan Beauveria bassiana) terhadap Aphis glycinespadaTanaman Kedelai”, Jurnal Agroekoteknologi Vol.5.No.1, (2): 8- 16, Januari 2017.

[2] Rudi Hariyanto, Khalimatus Sa'diyah, "Sistem Pakar Diagnosis Penyakit dan Hama Pada Tanaman Tebu Menggunakan Metode Certainty Factor”, Journal of Information Technology and Computer Science (JOINTECS), Vol. 3, No.1, hal 179-181, Januari 2018.

[3] Aryu Hanifah Aji1, M. Tanzil Furqon, Agus Wahyu Widodo, "Sistem Pakar Diagnosa Penyakit Ibu Hamil Menggunakan Metode Certainty Factor (CF)", Jurnal Pengembangan Teknologi Informasi dan Ilmu Komputer, Vol. 2, No. 5, , hlm. 2127-2134, Mei 2018.

[4] Amanah Febrian Indriani1, Eka Yuni Rachmawati2, Jevita Dwi Fitriana3 "Pemanfaatan Metode Certainty Factor dalam Sistem Pakar Diagnosa Penyakit pada Anak Utilization of Certainty Factor Method in Expert System of Disease Diagnosis in Children", Techno.COM, Vol. 17, No. 1, hal : 12-22 Februari 2018

[5] AS Sinaga, AS Girsang, "University Accreditation using Data Warehouse", IOP Conf. Series: Journal of Physics: Conf. Series 801 (2017).

[6] Irfan Aprison1, Nurul Hidayat, Budi Darma Setiawan, "Sistem Diagnosis Penyakit Pada Tanaman Melon Menggunakan Metode Forward Chaining - Certainty Factor", Jurnal Pengembangan Teknologi Informasi dan Ilmu Komputer, Vol. 2, No. 11, hlm. 5792-5798, November 2018. 